\title{
Validation of the graded prognostic assessment for lung cancer with brain metastases using molecular markers (lung-molGPA)
}

Carsten Nieder ${ }^{1,2^{*}}$, Mandy Hintz ${ }^{3}$, Oliver Oehlke ${ }^{3,4}$, Angelika Bilger ${ }^{3,4}$ and Anca L. Grosu 3,4

\begin{abstract}
Background: Many patients with brain metastases from non-small cell lung cancer have limited survival, while others survive for several years, depending on patterns of spread, EGFR and ALK alterations, among others. The purpose of this study was to validate a new prognostic model (Lung-molGPA) originally derived from a North American database.

Patients and methods: This retrospective study included 269 German and Norwegian patients treated with individualized approaches, always including brain radiotherapy. Information about age, extracranial spread, number of brain metastases, performance status, histology, EGFR and ALK alterations was collected. The Lung-molGPA score was calculated as described by Sperduto et al.

Results: Median survival was 5.4 months. The score predicted survival in patients with adenocarcinoma histology and those with other types. For example, median survival was 3.0, 6.2, 14.7 and 25.0 months in the 4 different prognostic strata for adenocarcinoma. The corresponding figures were 2.4, 5.5 and 12.5 months in the 3 different prognostic strata for non-adenocarcinoma.

Conclusions: These results confirm the validity of the Lung-molGPA in an independent dataset from a different geographical region. However, median survival was shorter in 6 of 7 prognostic strata. Potential explanations include lead time bias and differences in treatment selection, both brain metastases-directed and systemically.
\end{abstract}

Keywords: Brain metastases, Lung cancer, Radiotherapy, Prognostic factors

\section{Introduction}

One of the major challenges in the treatment of non-small cell lung cancer (NSCLC) is the high risk of brain metastases [1]. The continuous improvement of local treatment options, e.g., surgery and radiosurgery, which has paralleled development of better systemic therapies, has resulted in increasingly individualized approaches [2-6]. While some clinicians prefer simultaneous treatment of radiologically visible macroscopic metastases and microscopic disease, others recommend local therapy alone with

\footnotetext{
* Correspondence: carsten.nieder@nlsh.no

'Department of Oncology and Palliative Medicine, Nordland Hospital, 8092 Bodø, Norway

${ }^{2}$ Department of Clinical Medicine, Faculty of Health Sciences, University of Tromsø, 9037 Tromsø, Norway

Full list of author information is available at the end of the article
}

deferred salvage at the time of progression [7-9]. Efforts are also being made to identify patients who can safely continue systemic therapy without upfront brain radiotherapy, and patients whose prognosis is so poor that best supportive care should be considered [10-14]. Given that brain metastases can occur early or late during the disease trajectory, management decisions are not always simple and straightforward [15].

Prognostic tools have long been used to support decision making and to stratify participants in prospective clinical trials [16-19]. Scores such as the recursive partitioning analysis (RPA) [20] or graded prognostic assessment (GPA) [21, 22] have been validated in several studies and adopted widely $[20,21]$. Researchers have realized that these tools should be updated to reflect unique biological 
features of different primary tumor types, e.g. for breast and lung cancer [23-27]. Specifically for NSCLC a refined score integrating molecular features (EGFR and ALK alterations; Lung-molGPA) has recently been developed by a North American collaborative group, which previously has published the GPA [28]. The purpose of the present study was to validate the Lung-molGPA in an independent European patient population, hypothesizing that a validated score would gain wide acceptance and could replace the older RPA and GPA scores.

\section{Material and methods}

\section{Patients and treatment}

A retrospective study of 269 patients with irradiated brain metastases from NSCLC was performed. Patients managed with best supportive care rather than primary or post-operative radiotherapy were excluded. Treatment was individualized and consisted of focal therapies such as surgery, radiosurgery and stereotactic fractionated radiotherapy with or without whole-brain radiotherapy (WBRT) or upfront WBRT alone with total doses in the range of 20-40 Gy. Patients who failed to complete all fractions of radiotherapy were also included. Salvage treatment of intracranial lesions was individualized, too. All approaches mentioned above were considered at the time of relapse or progression. Systemic treatment was usually prescribed as judged appropriate by the patients' medical oncologists, both before and after brain-directed treatments. The patients were treated between 2005 and 2015 and identified from a previously described database [19, 29], which includes data from the radiotherapy centers in Bodø and Freiburg. Prognosis was estimated on the basis of age, Karnofsky performance status (KPS), extracranial metastases, number of brain metastases and NSCLC subtype as described in the original publication [28] and shown in Table 1. Differences to the widely used lung cancer-specific GPA score are also shown in the table.

\section{Statistical methods}

Actuarial survival from the first day of radiotherapy or from surgery was calculated employing the Kaplan-Meier method, and different groups were compared using the log-rank test (SPSS 23, IBM Corp., Armonk, NY, USA). Date of death was known in all patients. A multivariate Cox regression analysis was also performed (forward conditional method) and included all variables with $p$ value $\leq 0.05$ in univariate log-rank tests.

\section{Results}

\section{Patient characteristics}

The median age was 63 years (range 33-85). The median KPS was 80 (range 30-100). The most common initial treatment approach was primary WBRT alone (72\%), followed by surgery in combination with post-operative
Table 1 Baseline characteristics included in the Lung-molGPA (Sperduto et al. 2016 [28]): minimum point sum 0 (poor prognosis), maximum point sum 4 (good prognosis)

\begin{tabular}{lll}
\hline Parameter & Lung-molGPA & DS-GPA \\
\hline $\begin{array}{l}\text { Metastatic spread to } \\
\text { extracranial sides }\end{array}$ & 0 & 0 \\
Brain metastases only & 1 & 1 \\
Age $\geq 70$ years & 0 & 0 if $>60$ years \\
Age $<70$ years & 0.5 & 0.5 if $50-60$ years, \\
Karnofsky performance status $\leq 70$ & 0 & 1 if $<50$ years \\
Karnofsky performance status 80 & 0.5 & 0 if $<70$ \\
Karnofsky performance status $90-100$ & 1 & 0.5 if $70-80$ \\
Number of brain metastases $>4$ & 0 & 1 \\
Number of brain metastases 1-4 & 0.5 & 0 if $>3$ \\
EGFR or ALK positive & 1 & 0.5 if $2-3,1$ if 1 \\
& & not part of \\
\end{tabular}

DS-GPA diagnosis-specific graded prognostic assessment [22]

Table 2 Patient characteristics

\begin{tabular}{lll}
\hline Parameter & Number & Percent \\
\hline Male gender & 155 & 58 \\
Female gender & 114 & 42 \\
Adenocarcinoma & 192 & 71 \\
Non-adenocarcinoma & 77 & 29 \\
Extracranial metastases & 176 & 65 \\
No extracranial metastases & 93 & 35 \\
Single brain metastasis & 54 & 20 \\
2-4 brain metastases & 86 & 32 \\
$>4$ brain metastases & 129 & 48 \\
EGFR or ALK positive & 19 & 7 \\
Age $<70$ years & 200 & 74 \\
Age $\geq 70$ years & 69 & 26 \\
KPS $<70$ & 52 & 19 \\
KPS 70 & 70 & 26 \\
KPS 80 & 50 & 19 \\
KPS 90-100 & 97 & 36 \\
Upfront whole brain radiotherapy ${ }^{\text {a }}$ & 193 & 72 \\
Upfront neurosurgery & 57 & 21 \\
Upfront radiosurgery & 16 & 6 \\
Upfront stereotactic fractionated radiotherapy & 3 & 1 \\
Supportive care alone & 0 & 0 \\
\hline KPS Kanosky pefomance staus & &
\end{tabular}

KPS Karnofsky performance status

aincludes patients with delayed (salvage) neurosurgery, radiosurgery fractionated re-irradiation 
Table 3 Univariate analysis of prognostic factors for overall survival (log-rank test)

\begin{tabular}{lcc}
\hline Parameter & Median survival in months & $p$-value \\
\hline Male gender & 5.5 & \\
Female gender & 5.0 & 0.49 \\
Adenocarcinoma & 5.6 & \\
Non-adenocarcinoma & 4.5 & 0.87 \\
Extracranial metastases & 4.4 & \\
No extracranial metastases & 7.5 & 0.0001 \\
1-4 brain metastases & 6.0 & \\
$>4$ brain metastases & 4.6 & 0.04 \\
EGFR or ALK positive & 22.9 & \\
Not EGFR or ALK positive & 5.0 & 0.0001 \\
Age $<70$ years & 6.0 & 0.006 \\
Age $\geq 70$ years & 3.0 & \\
KPS $\leq 70$ & 2.5 & 0.0001 \\
KPS 80 & 7.0 & \\
KPS 90-100 & 11.0 &
\end{tabular}

KPS Karnofsky performance status

radiotherapy (21\%). Further patient characteristics are shown in Table 2.

\section{Lung-molGPA}

Most patients had unfavorable prognostic features, i.e. $0-1$ point in 110 patients $(41 \%)$ and $1.5-2$ points in
109 (41\%). Forty-two patients (16\%) had $2.5-3$ points and the remaining 8 (3\%) had 3.5-4 points. These four prognostic strata had significantly different median survival of $2.8,6.2,14.0$ and 25.0 months $(p<0.0001$, log-rank test pooled over all strata). Overall median survival was 5.4 months. Table 3 shows the results of univariate prognostic factors for survival. In multivariate Cox regression analysis KPS (dichotomized variable as in [28], $p=0.0001)$, extracranial metastases $(p=$ 0.002 ), age (dichotomized variable as in [28], $p=0.05$ ), EGFR or ALK alteration $(p=0.001)$ and number of brain metastases (dichotomized variable as in [28], $p=$ 0.05 ) were significant predictors of survival. Figure 1 and Table 4 show the survival outcomes of patients with adenocarcinoma. Figure 2 and Table 4 show the corresponding data in case of non-adenocarcinoma histology.

\section{Discussion}

We performed a retrospective validation study of the Lung-molGPA [28] in a European patient population, comparable to the previous validation of the DS-GPA [29]. The study population consisted mainly of patients with intermediate or poor prognosis who were judged not to be appropriate candidates for aggressive local therapies, such as surgery or stereotactic radiotherapy, but received active brain-metastases-directed therapy. This discrepancy likely explains why the median survival in our study was 5.4 months, while the North American

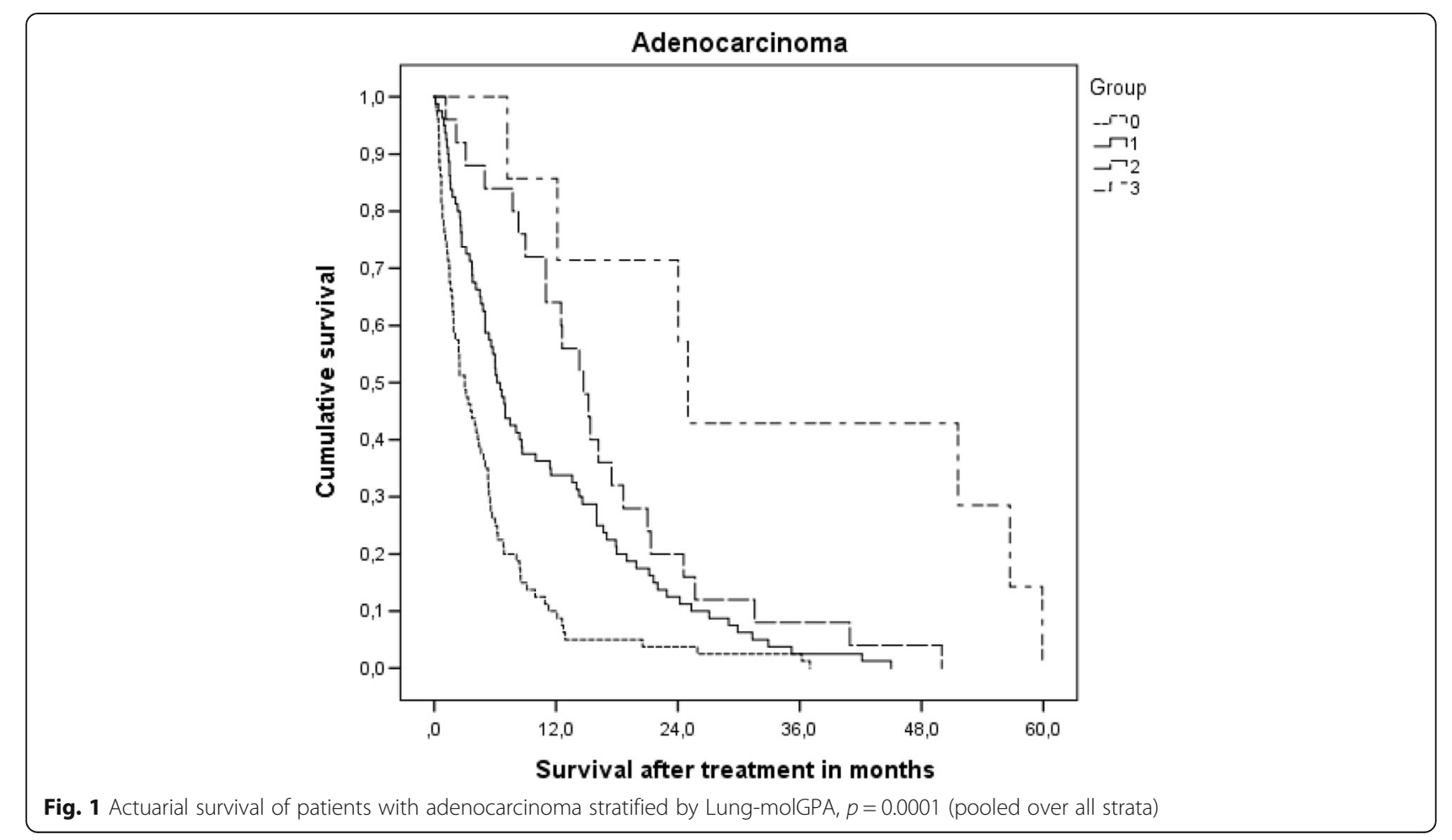


Table 4 Survival outcomes stratified by Lung-molGPA

\begin{tabular}{lllll}
\hline Group & Number & Median survival in months & 6-month probability & 12-month probability \\
\hline Adeno 0-1 p. & 80 & 3.0 & 26 & 10 \\
Adeno 1.5-2 p. & 80 & 6.2 & 54 & 34 \\
Adeno 2.5-3 p. & 25 & 14.7 & 84 & 64 \\
Adeno 3.5-4 p. & 8 & 25.0 & 100 & 88 \\
Other 0-1 p. & 30 & 2.4 & 10 & 10 \\
Other 1.5-2 p. & 29 & 5.5 & 48 & 21 \\
Other 2.5-3p. & 18 & 12.5 & 78 & 56 \\
\hline
\end{tabular}

patients survived for a median of 15.2 months (adenocarcinoma) and 9.2 months (non-adenocarcinoma). Other treatments (chemotherapy, targeted drugs, salvage of brain metastases) might have differed too, however, they were not recorded in any of the studies. Neither time interval from initial cancer diagnosis to brain metastases nor diagnostic setting (imaging in asymptomatic patients vs. clinical deficits) has been evaluated, resulting in potential lead time bias if North American patients were treated earlier. In principle, imbalances of patient characteristics such as KPS or mutation status could have contributed to the survival difference. However, median survival was shorter in 6 of 7 prognostic strata in our study. For example, patients with adenocarcinoma had inferior survival in all 4 strata (median 3.0 vs. 6.9 months; median 6.2 vs. 13.7 months; median 14.7 vs. 26.5 months; median 25.0 vs. 46.8 months). For non- adenocarcinoma the following differences emerged: median 2.4 vs. 5.3 months, median 5.5 vs. 9.8 months, and median 12.5 vs. 12.8 months. Most of these differences are clinically relevant and we therefore recommend additional studies in patients managed with different approaches in different regions of the world. The main result of our study was that the Lung-molGPA accurately reflects the prognostic impact of different baseline characteristics. This score seems to represent a useful improvement of its widely adopted ancestors such as RPA and DS-GPA [20-22].

Limitations of this study, which followed the methods used by Sperduto et al. [28], include the number of patients, statistical power of subgroup analyses, and retrospective design. Whereas the number of patients was limited in our database, they represent the total cohort of the two radiotherapy departments and consequently

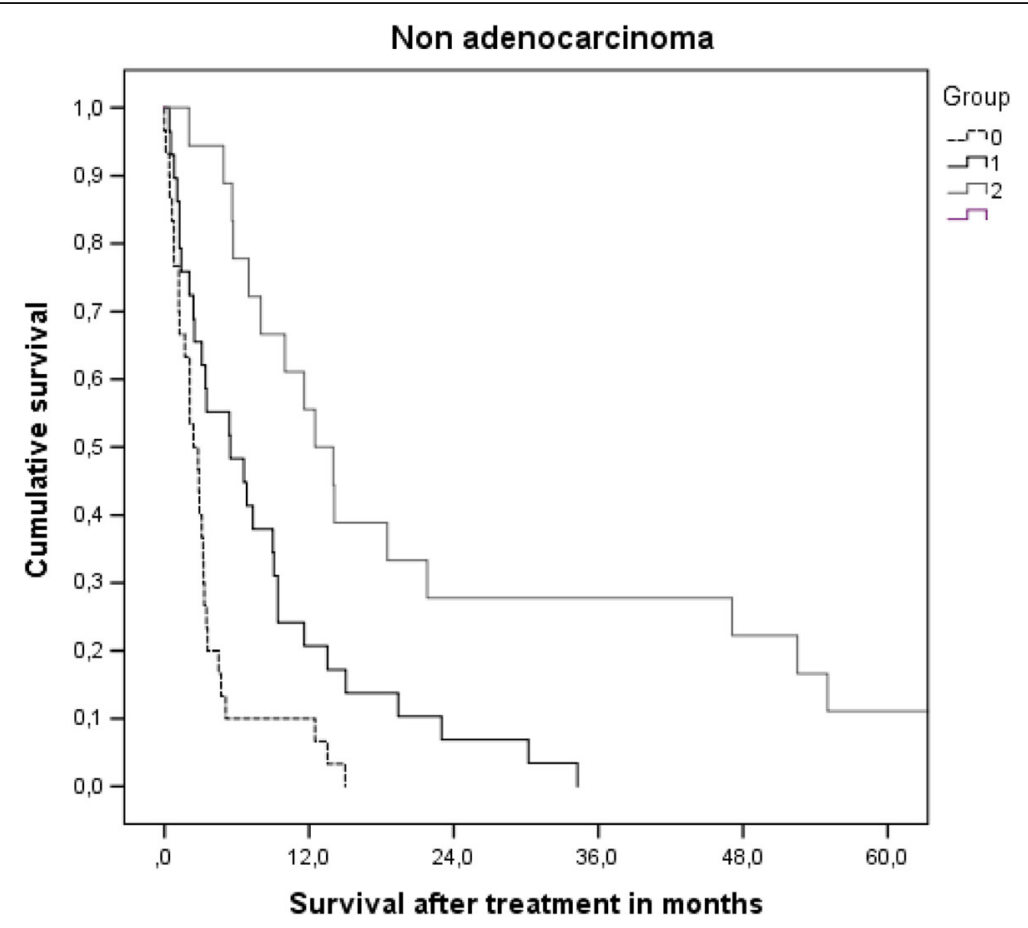

Fig. 2 Actuarial survival of patients with non-adenocarcinoma stratified by Lung-molGPA, $p=0.0001$ (pooled over all strata) 
express the daily practice at these academic hospitals. Given that patients managed with best supportive care were excluded, worse survival outcomes could be expected if one would analyze all patients with a brain metastases diagnosis, or in radiation oncology practices that would have offered WBRT to patients who were managed with best supportive care at the two institutions that participated in this study. The North American database included 2186 patients treated between 2006 and 2014. Radiosurgery was a component of care in more than $50 \%$ of patients with adenocarcinoma. In addition, neurosurgical resection was performed in selected patients. In our study, less than $30 \%$ received upfront surgery, radiosurgery or stereotactic fractionated radiotherapy. We have previously reported that increasing use of focal treatments such as radiosurgery and surgical resection and also of systemic treatment has resulted in prolonged survival, especially for patients with favorable prognostic features [30]. The observed survival differences between the present study and the one reported by Sperduto et al. [28] are in line with the hypothesis that continuous improvements of multimodal care translate into better outcome. With the advent of targeted drugs with high efficacy in molecularly-defined subgroups $[10,11,31]$, and possibly also immunotherapy [32], further improvement can be expected.

\section{Conclusions}

The data presented in this study confirm the validity of the Lung-molGPA in patients from a different geographical region. However, median survival was shorter in 6 of 7 prognostic strata. Potential explanations include differences in treatment selection, both brain metastasesdirected and with systemic agents. These hypotheses require additional studies.

\section{Abbreviations}

ALK: Anaplastic lymphoma kinase; EGFR: Epidermal growth factor receptor; GPA: Graded prognostic assessment; KPS: Karnofsky performance status; NSCLC: Non-small cell lung cancer; RPA: Recursive partitioning analysis; WBRT: Whole brain radiotherapy

\section{Acknowledgements}

The publication charges for this article have been funded by a grant from the publication fund of UiT - The Arctic University of Norway.

\section{Funding}

No funding to declare.

\section{Availability of data and materials}

The dataset supporting the conclusions of this article is available at request from the corresponding author, if intended to be used for meta-analyses.

\section{Authors' contributions}

$\mathrm{CN}$ and $\mathrm{MH}$ analyzed and interpreted the patient data regarding the prognostic model. CN and ALG drafted the manuscript. OO and AB collected references and were major contributors in writing the manuscript. All authors read and approved the final manuscript.

\section{Competing interests}

The authors declare that they have no competing interests.

\section{Consent for publication}

Not applicable.

\section{Ethics approval and consent to participate}

As a retrospective quality of care analysis, no approval from the Regional Committee for Medical and Health Research Ethics (REK Nord) was necessary. This research project was carried out according to our institutions' guidelines and with permission to access the patients' data.

\section{Publisher's Note}

Springer Nature remains neutral with regard to jurisdictional claims in published maps and institutional affiliations.

\section{Author details}

'Department of Oncology and Palliative Medicine, Nordland Hospital, 8092 Bodø, Norway. ${ }^{2}$ Department of Clinical Medicine, Faculty of Health Sciences, University of Tromsø, 9037 Troms $\varnothing$, Norway. ${ }^{3}$ Department of Radiation Oncology, University Hospital Freiburg, 79106 Freiburg, Germany. ${ }^{4}$ German Cancer Consortium (DKTK), Partner Site Freiburg, Freiburg, Germany.

Received: 21 April 2017 Accepted: 13 June 2017

Published online: 26 June 2017

\section{References}

1. Goncalves PH, Peterson SL, Vigneau FD, Shore RD, Quarshie WO, Islam K, Schwartz AG, Wozniak AJ, Gadgeel SM. Risk of brain metastases in patients with nonmetastatic lung cancer: analysis of the metropolitan Detroit surveillance, epidemiology, and end results (SEER) data. Cancer. 2016;122:1921-7.

2. Enders F, Geisenberger C, Jungk C, Bermejo JL, Warta R, von Deimling A, Herold-Mende C, Unterberg A. Prognostic factors and long-term survival in surgically treated brain metastases from non-small cell lung cancer. Clin Neurol Neurosurg. 2016;142:72-80.

3. Kępka L, Tyc-Szczepaniak D, Bujko K, Olszyna-Serementa M, Michalski W, Sprawka A, Trąbska-Kluch B, Komosińska K, Wasilewska-Teśluk E, Czeremszyńska B. Stereotactic radiotherapy of the tumor bed compared to whole brain radiotherapy after surgery of single brain metastasis: results from a randomized trial. Radiother Oncol. 2016;121:217-24.

4. Bilger A, Milanovic D, Lorenz H, Lorenz H, Oehlke O, Urbach H, Schmucker M, Weyerbrock A, Nieder C, Grosu AL. Stereotactic fractionated radiotherapy of the resection cavity in patients with one to three brain metastases. Clin Neurol Neurosurg. 2016;142:81-6.

5. Navarria P, Pessina F, Cozzi L, Ascolese AM, De Rose F, Fogliata A, Franzese C, Franceschini D, Tozzi A, D'Agostino G, Comito T, Iftode C, Maggi G, Reggiori G, Bello L, Scorsetti M. Hypo-fractionated stereotactic radiotherapy alone using volumetric modulated arc therapy for patients with single, large brain metastases unsuitable for surgical resection. Radiat Oncol. 2016;11:76.

6. Lischalk JW, Oermann E, Collins SP, Nair MN, Nayar W, Bhasin R, Voyadzis JM, Rudra S, Unger K, Collins BT. Five-fraction stereotactic radiosurgery (SRS) for single inoperable high-risk non-small cell lung cancer (NSCLC) brain metastases. Radiat Oncol. 2015;10:216.

7. Greto D, Scoccianti S, Compagnucci A, Arilli C, Casati M, Francolini G, Cecchini S, Loi M, Desideri I, Bordi L, Bono P, Bonomo P, Meattini I, Detti B, Livi L. Gamma knife radiosurgery in the management of single and multiple brain metastases. Clin Neurol Neurosurg. 2016;141:43-7.

8. Zindler JD, Slotman BJ, Lagerwaard FJ. Patterns of distant brain recurrences after radiosurgery alone for newly diagnosed brain metastases: implications for salvage therapy. Radiother Oncol. 2014;112:212-6.

9. Nieder C, Grosu AL, Gaspar LE. Stereotactic radiosurgery (SRS) for brain metastases: a systematic review. Radiat Oncol. 2014;9:155.

10. Gadgeel SM, Shaw AT, Govindan R, Gandhi L, Socinski MA, Camidge DR, De Petris L, Kim DW, Chiappori A, Moro-Sibilot DL, Duruisseaux M, Crino L, De Pas T, Dansin E, Tessmer A, Yang JC, Han JY, Bordogna W, Golding S, Zeaiter A, Ou SI. Pooled analysis of CNS response to alectinib in two studies of pretreated patients with ALK-positive non-small-cell lung cancer. J Clin Oncol. 2016;34:4079-85.

11. Kashima J, Okuma Y, Miwa M, Hosomi Y. Survival of patients with brain metastases from non-small cell lung cancer harboring EGFR mutations 
treated with epidermal growth factor receptor tyrosine kinase inhibitors. Med Oncol. 2016:33:129.

12. Mulvenna P, Nankivell M, Barton R, Faivre-Finn C, Wilson P, McColl E, Moore B, Brisbane I, Ardron D, Holt T, Morgan S, Lee C, Waite K, Bayman N, Pugh C, Sydes B, Stephens R, Parmar MK, Langley RE. Dexamethasone and supportive care with or without whole brain radiotherapy in treating patients with non-small cell lung cancer with brain metastases unsuitable for resection or stereotactic radiotherapy (QUARTZ): results from a phase 3, non-inferiority, randomised trial. Lancet. 2016;388:2004-14.

13. Nieder C, Norum J, Dalhaug A, Aandahl G, Pawinski A. Radiotherapy versus best supportive care in patients with brain metastases and adverse prognostic factors. Clin Exp Metastasis. 2013;30:723-9.

14. Soon YY, Leong CN, Koh WY, Tham IW. EGFR tyrosine kinase inhibitors versus cranial radiation therapy for EGFR mutant non-small cell lung cancer with brain metastases: a systematic review and meta-analysis. Radiother Oncol. 2015;114:167-72.

15. Hendriks LE, Troost EG, Steward A, Bootsma GP, De Jaeger K, van den Borne $B E$, Dingemans AM. Patient selection for whole brain radiotherapy (WBRT) in a large lung cancer cohort: Impact of a new Dutch guideline on brain metastases. Acta Oncol. 2014;53:945-51.

16. Nieder C, Bremnes RM, Andratschke NH. Prognostic scores in patients with brain metastases from non-small cell lung cancer. J Thorac Oncol. 2009;4:1337-41.

17. Kaul D, Angelidis A, Budach V, Ghadjar P, Kufeld M, Badakhshi H. Prognostic indices in stereotactic radiotherapy of brain metastases of non-small cell lung cancer. Radiat Oncol. 2015;10:244.

18. Barnholtz-Sloan JS, Yu C, Sloan AE, Vengoechea J, Wang M, Dignam JJ, Vogelbaum MA, Sperduto PW, Mehta MP, Machtay M, Kattan MW. A nomogram for individualized estimation of survival among patients with brain metastasis. Neuro Oncol. 2012;14:910-8.

19. Nieder C, Hintz M, Grosu AL. Predicted survival in patients with brain metastases from colorectal cancer: Is a current nomogram helpful? Clin Neurol Neurosurg. 2016;143:107-10.

20. Gaspar LE, Scott C, Murray K, Curran W. Validation of the RTOG recursive partitioning analysis (RPA) classification for brain metastases. Int J Radiat Oncol Biol Phys. 2000;47:1001-6.

21. Sperduto PW, Chao ST, Sneed PK, Luo X, Suh J, Roberge D, Bhatt A, Jensen AW, Brown PD, Shih H, Kirkpatrick J, Schwer A, Gaspar LE, Fiveash JB, Chiang $\checkmark$, Knisely J, Sperduto CM, Mehta M. Diagnosis-specific prognostic factors, indexes, and treatment outcomes for patients with newly diagnosed brain metastases: a multi-institutional analysis of 4,259 patients. Int J Radiat Oncol Biol Phys. 2010;77:655-61.

22. Sperduto PW, Kased N, Roberge D, Xu Z, Shanley R, Luo X, Sneed PK, Chao ST, Weil RJ, Suh J, Bhatt A, Jensen AW, Brown PD, Shih HA, Kirkpatrick J, Gaspar LE, Fiveash JB, Chiang V, Knisely JP, Sperduto CM, Lin N, Mehta M. Summary report on the graded prognostic assessment: an accurate and facile diagnosis-specific tool to estimate survival for patients with brain metastases. J Clin Oncol. 2012;30:419-25.

23. Nieder C, Marienhagen K, Dalhaug A, Aandahl G, Haukland E, Pawinski A. Prognostic models predicting survival of patients with brain metastases: integration of lactate dehydrogenase, albumin and extracranial organ involvement. Clin Oncol (R Coll Radiol). 2014;26:447-52.

24. Sperduto PW, Kased N, Roberge D, Chao ST, Shanley R, Luo X, Sneed PK, Suh J, Weil RJ, Jensen AW, Brown PD, Shih HA, Kirkpatrick J, Gaspar LE, Fiveash JB, Chiang V, Knisely JP, Sperduto CM, Lin N, Mehta M. The effect of tumor subtype on the time from primary diagnosis to development of brain metastases and survival in patients with breast cancer. J Neurooncol. 2013;112:467-72.

25. Sperduto PW, Yang TJ, Beal K, Pan H, Brown PD, Bangdiwala A, Shanley R, Yeh N, Gaspar LE, Braunstein S, Sneed P, Boyle J, Kirkpatrick JP, Mak KS, Shih HA, Engelman A, Roberge D, Arvold ND, Alexander B, Awad MM, Contessa J, Chiang V, Hardie J, Ma D, Lou E, Sperduto W, Mehta MP. The effect of gene alterations and tyrosine kinase inhibition on survival and cause of death in patients with adenocarcinoma of the lung and brain metastases. Int J Radiat Oncol Biol Phys. 2016;96:406-13.

26. Nieder C, Grosu AL, Marienhagen K, Andratschke NH, Geinitz H. Non-small cell lung cancer histological subtype has prognostic impact in patients with brain metastases. Med Oncol. 2012;29:2664-8.

27. Ma LH, Li G, Zhang HW, Wang ZY, Dang J, Zhang S, Yao L. The effect of non-small cell lung cancer histology on survival as measured by the graded prognostic assessment in patients with brain metastases treated by hypofractionated stereotactic radiotherapy. Radiat Oncol. 2016;11:92.
28. Sperduto PW, Yang TJ, Beal K, Pan H, Brown PD, Bangdiwala A, Shanley R, Yeh N, Gaspar LE, Braunstein S, Sneed P, Boyle J, Kirkpatrick JP, Mak KS, Shih HA, Engelman A, Roberge D, Arvold ND, Alexander B, Awad MM, Contessa J, Chiang V, Hardie J, Ma D, Lou E, Sperduto W, Mehta MP. Estimating survival in patients with lung cancer and brain metastases: An update of the graded prognostic assessment for lung cancer using molecular markers (Lung-molGPA). JAMA Oncol. 2016. doi: 10.1001/jamaoncol.2016.3834.

29. Nieder C, Andratschke NH, Geinitz H, Grosu AL. Diagnosis-specific graded prognostic assessment score is valid in patients with brain metastases treated in routine clinical practice in two European countries. Med Sci Monit. 2012;18:CR450-5.

30. Nieder C, Spanne O, Mehta MP, Grosu AL, Geinitz H. Presentation, patterns of care, and survival in patients with brain metastases: what has changed in the last 20 years? Cancer. 2011;117:2505-12.

31. Zheng Z, Jin X, Lin B, Su H, Chen H, Fei S, Zhao L, Deng X, Xie D, Xie C. Efficacy of second-line tyrosine kinase inhibitors in the treatment of metastatic advanced non-small-cell lung cancer harboring exon 19 and 21 EGFR mutations. J Cancer. 2017;8:597-605.

32. Reinmuth N, Reck M. Immunotherapy for lung cancer. Oncol Res Treat. 2016;39:360-8.

\section{Submit your next manuscript to BioMed Central and we will help you at every step:}

- We accept pre-submission inquiries

- Our selector tool helps you to find the most relevant journal

- We provide round the clock customer support

- Convenient online submission

- Thorough peer review

- Inclusion in PubMed and all major indexing services

- Maximum visibility for your research

Submit your manuscript at www.biomedcentral.com/submit
C Biomed Central 